\title{
Ulnar artery entrapment of the median nerve
}

\author{
G Andrew Robertson MPhil FRCS FRCSC, Michael W Neumeister MD FRCSC \\ Section of Plastic Surgery, Health Science Centre, Winnipeg, Manitoba
}

GA Robertson, MW Neumeister. Ulnar artery entrapment of the median nerve. Can J Plast Surg 1999;7(1):35-37.

Entrapment of the median nerve is a common focal neuropathy. Many etiological factors have been implicated in this neural compression including inflammation, synovial hypertrophy, ligamentous or fascial bands, tumours, aberrant muscles, trauma, endocrinopathies and vascular lesions. Marked elongation and torsion of the peripheral arteries is an extremely rare cause of this focal neuropathy. A unique case of median nerve entrapment by the ulnar artery in the distal forearm is presented.

Key words: Median nerve, Ulnar artery

\section{Compression du nerf médian par l'artère cubitale}

RÉSUMÉ : La compression du nerf médian est une neuropathie focale courante. De nombreux facteurs étiologiques ont été incriminés dans cette compression neurale, y compris l'inflammation, l'hypertrophie synoviale, les brides ligamenteuses ou aponévrotiques, les tumeurs, les aberrations musculaires, les traumatismes, certaines endocrinopathies et lésions vasculaires. L'élongation marquée et la torsion des artères périphériques sont des causes extrêmement rares de neuropathie focale. On présente ici un cas unique de compression du nerf médian par l'artère cubitale à l'avant-bras distal.

$\mathrm{E}^{\mathrm{s}}$ ntrapment of the median nerve is a common focal neuropathy. Many etiological factors have been implicated in this neural compression including inflammation, synovial hypertrophy, ligamentous or fascial bands, tumours, aberrant muscles, trauma, endocrinopathies and vascular lesions. Vascular leashes, aneurysms, thrombosis, malformations, vascular tumours and anomalous vessels are among the vascular causes of median nerve entrapment. Marked elongation and torsion of the peripheral arteries is an extremely rare cause of this focal neuropathy.

A unique case of median nerve entrapment by the ulnar artery in the distal forearm is presented.

\section{CASE PRESENTATION}

A 47-year-old woman presented with a two-year history of progressive numbness to her right hand. The symptoms were worse at night, and she occasionally experienced pain, numbness and tingling in the thumb, and index and middle fingers. Postural changes, splinting or cessation from repetitive wrist activities provided little relief. The patient also complained

Correspondence and reprints: Dr GA Robertson, Section of Plastic Surgery, Rm Gc 413, Health Science Centre, 820 Sherbrook Street, Winnipeg, Manitoba R3A 1R9. Telephone 204-787-1485, fax 204-787-4837 of weakness in grip strength in the few months before presentation. Examination revealed a transverse pulsatile mass on the volar aspect of the distal forearm approximately $5 \mathrm{~cm}$ from the distal wrist crease (Figure 1). A bruit was not auscultated. There was marked tingling and dysesthesia in the thumb, and index and long fingers on gentle percussion (Tinel's sign) of the mass. Provocative wrist flexion did not induce dysesthesia. There was no wasting of the thenar muscles. Grip strength, motor function and power were objectively equal to those of the unaffected left hand. Twopoint discrimination was normal.

Because of the pulsatile mass on the volar forearm, an angiogram was performed (Figure 2). An anomalous torsion of the ulnar artery was evident with the ulnar artery veering to the radial side of the forearm, turning sharply back to the ulnar side $5 \mathrm{~cm}$ proximal to the wrist, travelling transversely to the ulnar side and taking a final $90^{\circ}$ turn to enter Guyon's canal.

Nerve conduction studies revealed a reduction in the conduction velocity of the median nerve at the level of the pulsatile mass (aberrant ulnar artery).

Exploration of the median nerve was performed under loupe magnification. The limb was not exsanguinated to maintain the fullness of the ulnar artery. Following dissection through the fascia, the ulnar artery was observed to course 


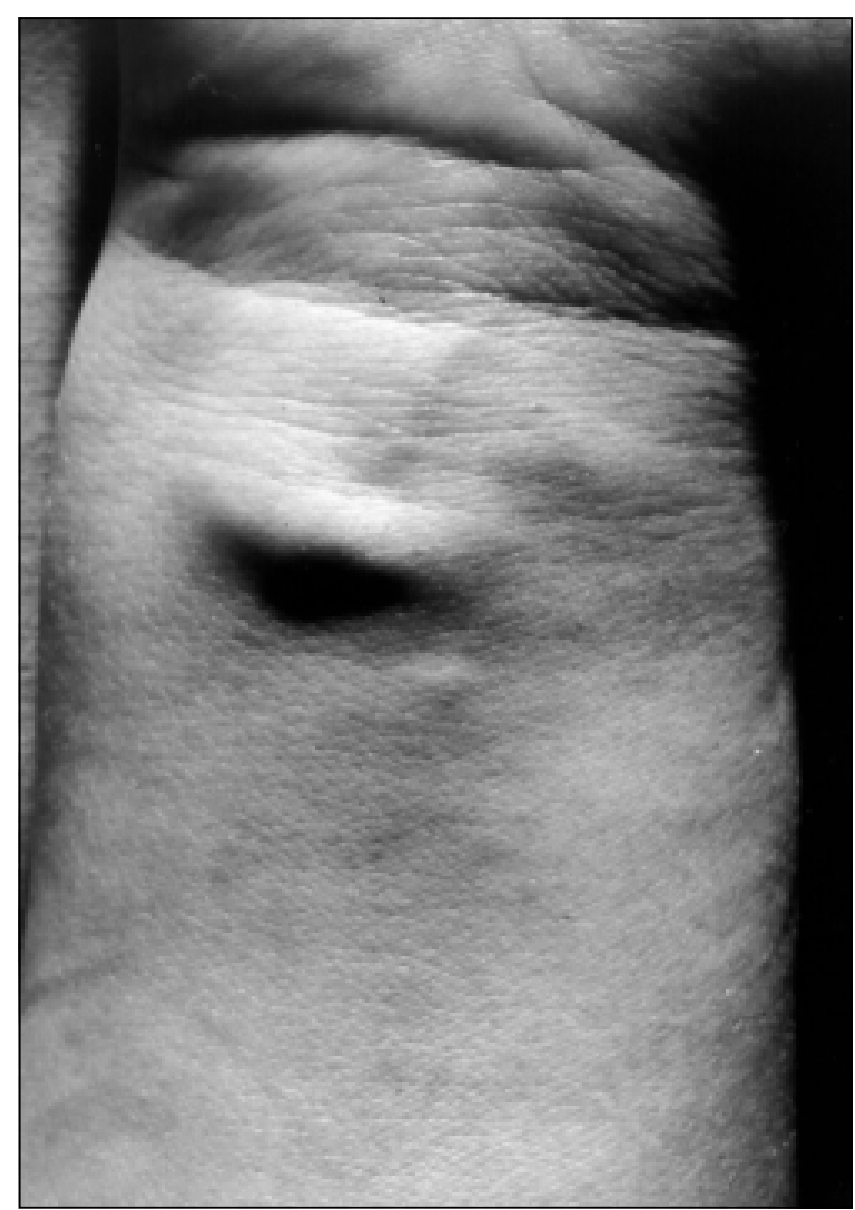

Figure 1) Transverse pulsatile mass in distal forearm

over the median nerve. The artery was tented by a radially based band of fascia (Figure 3). Release of the fascial band and ulnar relocation of the artery were performed (Figure 4). The carpal ligament was then released. Hemostasis was secured.

Postoperatively, there were no further episodes of numbness or dysesthesia in the radial three digits. Subjectively and objectively, the patient remains symptom free.

\section{DISCUSSION}

Symptomatic entrapment of the median nerve in the forearm and wrist has been well documented (1). There are numerous reports of vascular compression of the median nerve (1-4). These reports, however, cite vascular leashes, aneurysms, arteriovenous malformations or vascular tumours as the causative factor. These factors are usually found more proximally, causing the pronator syndrome (4). Compression of the median nerve by an aberrant ulnar artery has not been previously reported.

The ulnar artery's aberrant course cross the media nerve and was secured by a radially directed fascial band. It was evident that this was the site of entrapment. Clinically, there was a Tinel's sign at this precise location (over the pulsatile

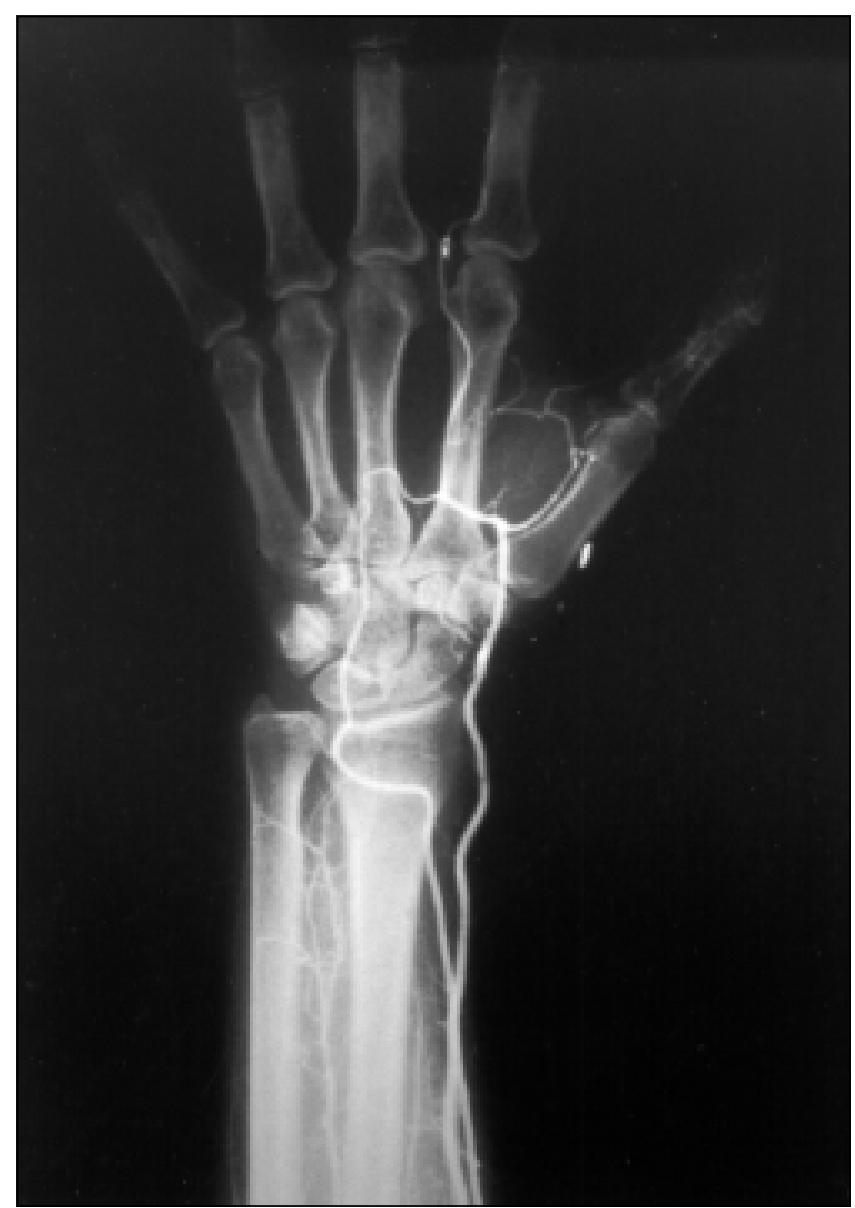

Figure 2) Angiogram showing aberrant ulnar artery

mass). The conduction studies that isolated the lesion to this location corroborate the clinical findings. Although there is documentation of anomalous pathways of the ulnar artery, such a tortuous route of this artery is rare. Arterial elongation, enlargement and dilatation have been described for intracranial vessels with subsequent cranial nerve entrapment $(5,6)$. Boeri and Passerini (7) descriptively coined the term ' $\mathrm{m}$ egadolichobasilar syndrome' to describe these cranial nerve entrapments. Segal et al (8) noted the paucity in the literature of this vascular anomaly in peripheral nerves. They report a case of ulnar nerve entrapment resulting from a tortuous ulnar artery. An anomalous median artery has been associated with anterior interosseous syndrome (2). Nothing in the embryological development of the blood vessels of the upper limb indicates how the present aberrant course could have arisen.

The reason for the late onset of symptoms remains unclear. This continues to be a source of puzzlement in entrapment neuropathies where vascular leashes (including aberrant pathways) and anomalous muscles are implicated. An anomalous course of the ulnar artery resulting in median nerve entrapment has not been reported before but represents another causative factor in focal median neuropathies. 


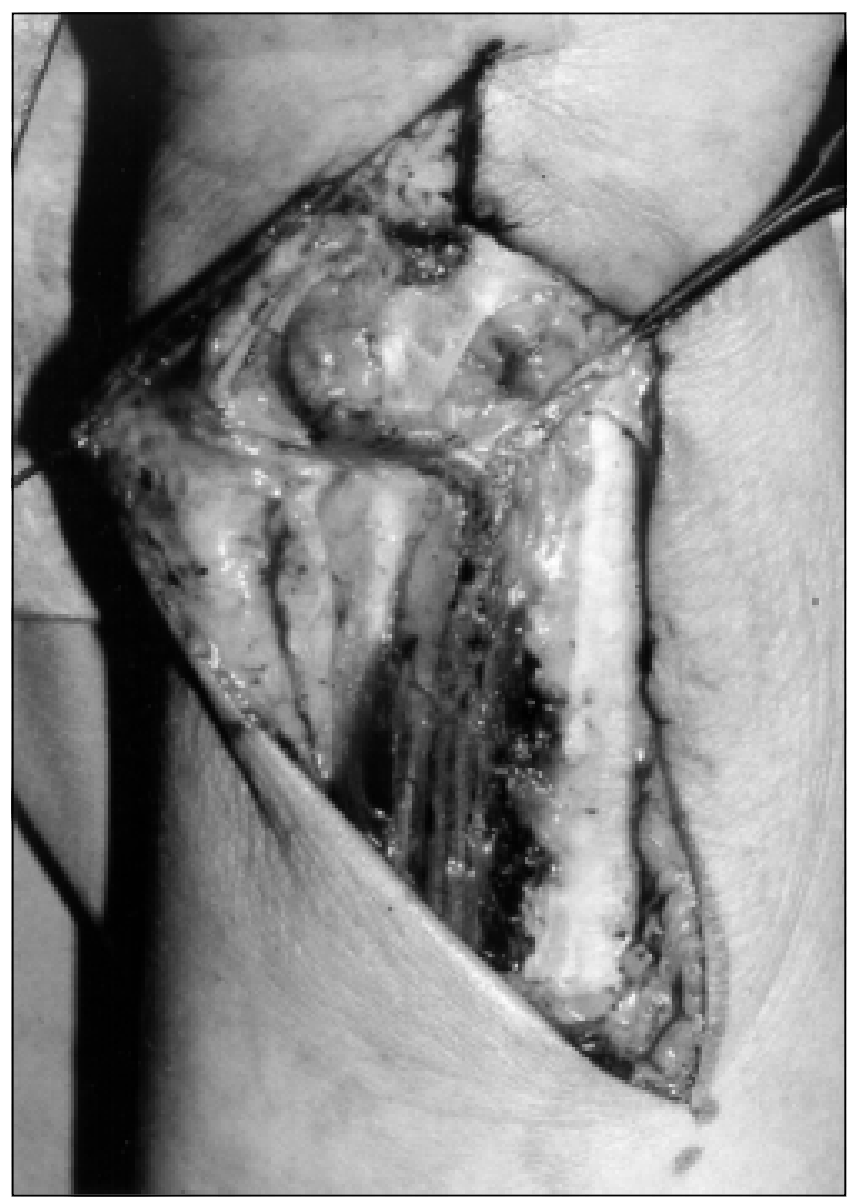

Figure 3) Intraoperative appearance: Ulnar artery crossing median nerve at site of Tinel's sign

\section{REFERENCES}

1. Lundborg G, Dahlin LB. The pathophysiology of nerve compression. Hand Clin 1992;8:215-27.

2. Proudman TW, Menz PJ. An anomaly of the median artery associated with the anterior interosseous nerve syndrome. J Hand Surg [Br] 1992;17:507-9.

3. Ergungor MF, Kars HZ, Yalin R. Median neuralgia caused by brachial pseudoaneurysm. Neurosurgery 1989;24:924-5.

4. Jones NF, Ming NL. Persistent median artery as a cause of pronator syndrome. J Hand Surg [Am] 1988;13:728-32.

5. Yu YL, Moseley IF, Pullicino P, McDonald WI. The clinical

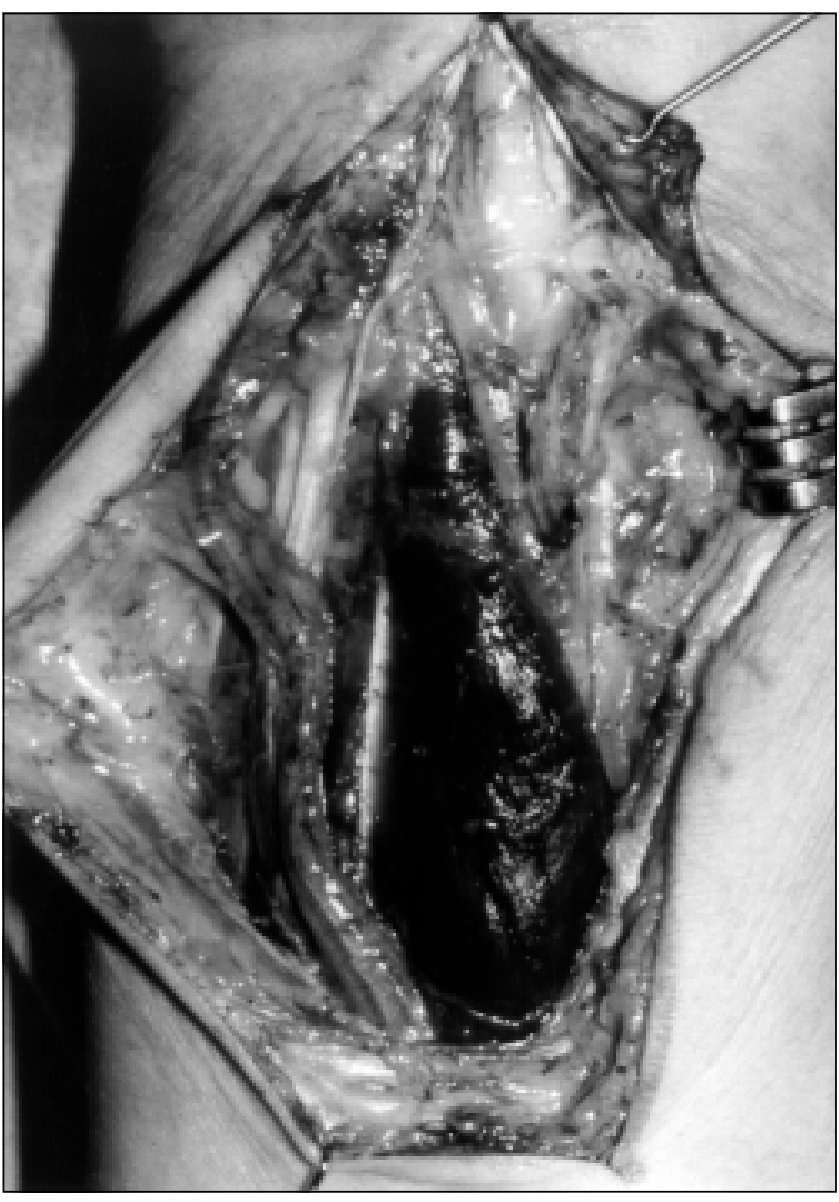

Figure 4) Relocation of ulnar artery to correct anatomical position

picture of ectasia of the intracerebral arteries. J Neurol Neurosurg Psychiatry 1982;45:29-36.

6. Mendelowitsch A, Radue EW, Gratzl O. Aneurysm, arteriovenous malformation and arteriovenous fistula in posterior fossa compression syndrome. Eur Neurol 1990;30:338-42.

7. Boeri R, Passerini A. The megadolichobasilar anomaly. J Neurol Sci 1964;1:475-84

8. Segal R, Machiraju U, Larkins M. Tortuous peripheral arteries: a cause of focal neuropathy. Case report. J Neurosurg 1992;76:701-4. 